\title{
Glycolipid Transfer Protein Mediated Transfer of Glycosphingolipids between Membranes:
}

\author{
A Model for Action Based on Kinetic and Thermodynamic Analyses†
}

\author{
Chetan S. Rao ${ }^{*} \ddagger$, Xin Lin $\ddagger, \S$, Helen M. Pike ${ }^{\ddagger}$, Julian G. Molotkovsky ${ }^{\|}$, and Rhoderick E. \\ Brown $^{\star}, \ddagger$
}

The Hormel Institute, University of Minnesota, 801 16th Avenue Northeast, Austin, Minnesota, and The Shemyakin-Ovchinnikov Institute of Bioorganic Chemistry, Russian Academy of Sciences, MiklukhoMaklaya Street, 16/10, 117871 Moscow, GSP-7 V-437, Russia

$\ddagger$ University of Minnesota.

IIShemyakin—Ovchinnikov Institute of Bioorganic Chemistry.

\section{Abstract}

Glycolipid transfer protein (GLTP) catalyzes the intermembrane transfer of lipids that have sugars $\beta$-linked to either diacylglycerol or ceramide backbones, including simple glycosphingolipids (GSLs) and gangliosides. The present study provides a quantitative understanding of GLTP action involving bilayer vesicles that have high and low curvature stress, i.e., small and large unilamellar vesicles (SUVs and LUVs). When the GSL intervesicular transfer was monitored in real time using an established fluorescence resonance energy approach, the initial GSL transfer rates $\left(v_{0}\right)$ and net transfer equilibrium $\left(K_{\mathrm{eq}}\right)$ were determined for GLTP-mediated transfer from SUVs and LUVs over the temperature range of $30-44{ }^{\circ} \mathrm{C}$. $v_{0}$ exhibited a linear dependence with respect to varying GLTP concentrations (0-143 $\mathrm{nM}$ range) in SUVs and LUVs, suggesting a first order dependence on the GLTP bulk concentration. Thermodynamic parameters associated with the GLTP-GSL transitionstate complex and GSL net transfer were determined from linear Arrhenius and van't Hoff plots, respectively. Although initial transfer rates were lower for LUVs than for SUVs, the activation energy barriers were higher for LUVs, while the Gibbs's free energy of the transition states were similar. The formation of a transition-state complex was predominantly enthalpy driven, whereas the net transfer of GSLs was mainly entropy driven. The rate-limiting step for GLTP action appeared to be the surface processes leading to the GLTP-GSL complex formation and release associated with a shuttle/carrier mode of action. Because surface processes leading to the GLTP-GSL complex formation were limiting for GLTP action with SUVs and LUVs, it was concluded that GLTP is likely to be a valuable tool to probe and manipulate GSL environments in membranes.

Glycosphingolipids (GSLs) $)^{1,2}$ are sugar-containing sphingolipid molecules that participate in various cell-surfacerelated processes, such as cell differentiation, transmembrane signaling, cell recognition, and toxin binding $(1,2)$. These lipids show a great degree of transbilayer asymmetry (3), an essential attribute that enhances exposure of their sugar headgroups at the cell surface. The lateral organization of GSLs in membranes is driven by their tendency to mix

\footnotetext{
${ }^{\dagger}$ This research study was supported by NIH/NIGMS GM45928 and The Hormel Foundation.

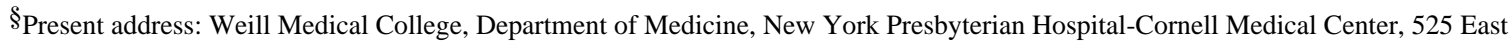
68th St., Room F-203A, New York, NY 10021.

${ }^{*}$ To whom correspondence should be addressed: The Hormel Institute, University of Minnesota, 801 16th Ave. NE, Austin, MN 55912-3698. Telephone: 507-433-8804. Fax: 507-437-9606. E-mail: reb@umn.edu or rebrown@ hi.umn.edu (R.E.B.); chetan@hi.umn.edu (C.S.R.).
} 
nonrandomly with many membrane lipids and to associate with cholesterol and sphingomyelin to form lipid rafts, transient microdomains that function as organizational platforms in transmembrane signal transduction mediated by lipidanchored kinases and glycosylphosphatidylinositol-anchored proteins (4). Because of their importance in various essential cell processes, the trafficking and expression of GSLs from their site of synthesis in the ER-Golgi complex must be effectively coordinated and controlled. Proteins with the potential to affect these and other important GSL-mediated processes need to be investigated and better understood.

Selective enhancement of GSL intermembrane transfer by soluble proteins was first discovered in the membrane-free cytosolic extract of bovine spleen $(5,6)$. Glycolipid transfer proteins (GLTPs) that exhibit in vitro transfer of GSLs have since been isolated from a variety of sources such as spinach choloroplasts and mammalian brain, liver, and kidney (7-10). Purification of the spleen and brain GLTPs has revealed monomers with molecular weights of $22-24 \mathrm{kDa}$ and an absolute specificity for glycolipids in which the initial sugar residue is $\beta$-linked to the hydrophobic backbone (11-14). Although GLTP behavior has been investigated in vitro, many aspects of the structure-function relationships of GLTP as well as its mechanism of action are not wellunderstood. Understanding the basic mechanism involved in GLTP-mediated intermembrane transfer is important not only for obtaining clues into its in vivo function but also for effectively using GLTP as a tool to manipulate and probe GSL raft composition in biomembranes.

\footnotetext{
${ }^{1}$ Abbreviations

GSL

glycosphingolipid

GLTP

glycolipid transfer protein

POPC

1-palmitoyl-2-oleoyl-sn-glycero-3-phosphocholine

DPPA

1,2-dipalmitoyl-sn-glycero-3-phosphate

PITP

phosphatidylinositol transfer protein

GalCer

galactosylceramide

AV-GalCer

$N$-[(11E)-12-(9-anthryl)-11-dodecenoyl]-1-O- $\beta$-galactosylsphingosine

Per-PC

rac-1,2-di-oleoyl-3-[9-(3-perylenoyl)nonanoyl]-sn-glycero-3-phosphocholine

RET

fluorescence resonance energy transfer

SUV

small unilamellar vesicle

LUV

large unilamellar vesicle

${ }^{2}$ Kinetic and thermodynamic parameters: $v_{0}$, the initial transfer velocity; $k_{+3}$, desorption constant of the GLTP—GSL complex; $k_{-1}$, desorption constant of GLTP from the donors; $k_{+1}$, adsorption constant of GLTP to the donor; $K_{\mathrm{M}}^{\mathrm{D}}$, two-dimensional Michalis-Mententype constant for the GLTP-GSL complex; $\Delta H^{\ddagger}$, enthalpy of transition state; $\Delta G^{\ddagger}$, Gibbs free energy of the transition state; $\Delta S^{\ddagger}$, entropy of the transition state; $\Delta H_{\mathrm{eq}}$, enthalpy of overall transfer; $\Delta G_{\mathrm{eq}}$, Gibbs free energy of overall transfer; $\Delta S_{\mathrm{eq}}$, entropy of overall transfer; $K_{\text {eq, }}$, equilibrium constant for overall transfer.
} 
The transfer mechanism of GLTP remains enigmatic for two reasons. First, previous studies with porcine GLTP revealed surprisingly low protein—glycolipid binding ratios ( $~ 8: 1)$ in soluble GLTP—glycolipid complexes (11), raising uncertainty as to whether GLTP functions in a "lipid carrier/shuttle" mode. Also, earlier studies with bovine GLTP were performed with partially purified protein preparations, complicating accurate assessment of GLTP—glycolipid complexation ratios $(7,15)$. Second, kinetic analyses of GLTP action to date have been based on simple first-order rate equations that are insufficient for dissecting the physicochemical steps involved in the transfer process $(16,17)$. Although such analyses have helped to provide generalized insights into GLTP-liposome interactions, a more comprehensive kinetic treatise that includes analysis of thermodynamic relationships associated with the GLTP-mediated intervesicular transfer process is needed to quantitatively assess the effects of membrane structure and composition on GLTP action. Many previous studies of in vitro GLTP function also have involved small unilamellar vesicles (SUVs) $(16,17)$. A special feature of SUV systems is the associated membrane curvature stress, a feature that can influence proteinmembrane interactions. Sensitivity of a protein to membrane curvature might also have implications for its cellular functionality.

The goals of this study were (1) to develop a comprehensive model of the basic mechanism involved in GLTP action and (2) to quantitatively assess the capacity of GLTP for interacting with large unilamellar vesicles (LUVs) compared with curvature-stressed vesicles, i.e., SUVs. These goals were achieved using real-time fluorescence resonance energy transfer measurements of glycolipid intervesicular transfer. Compared to earlier modeling studies of lipid transfer proteins, a novel consideration of our treatise was the emphasis on the mechanistic details associated with the transfer of a minority glycolipid from a membrane comprised mostly of "nonsubstrate" phosphatidylcholine. Included in such considerations is the potential role of lateral diffusion of glycolipid and GLTP bound to the membrane in formation of the GLTPGSL transition-state complex. Also, the thermodynamic parameters associated with the protein-mediated transfer process were analyzed using both SUVs and LUVs leading to the conclusion that GLTP is a potentially useful tool for probing GSL environments in membranes.

\section{EXPERIMENTAL PROCEDURES}

\section{Lipids}

1-Palmitoyl-2-oleoylphosphatidylcholine (POPC) and porcine brain galactosylceramide (GalCer) were purchased from Avanti Polar Lipids (Alabaster, AL). The fluorescent probes, $N$-[(11E)-12-(9-anthryl)-11-dodecenoyl]-1- $O$ - $\beta$-galactosylsphingosine [AV-GalCer] and rac-1,2-dioleoyl-3-[9-(3-perylenoyl)-nonanoyl]-sn-glycero-3-phosphocholine [Per-PC] were prepared as described earlier $(18,19)$. Stock concentrations of phospholipids were quantitated using the method of Bartlett (20), of galactosylceramide, by gravimetric analyses, and of fluorescent lipids, using their extinction coefficients $(14,17)$.

\section{GLTP}

Recombinant human GLTP was generated using molecular cloning, heterologous expression, and purification approaches described previously (21-23). Protein purity and concentration were determined by SDS-PAGE (22) and using bicinchoninic acid (24), respectively. The open-reading frame of human fibroblast mRNA $^{3}$ encodes GLTP that is $98 \%$ homologous to

\footnotetext{
${ }^{3}$ Nucleotide sequences for human skin fibroblast GLTP (AF209704), bovine brain GLTP (AF209701 and NM016433), porcine brain GLTP (AF209702 and NM016433), and mouse JB6 epidermal cell GLTP (AF209703) have been deposited in the NCBI GenBank database. The amino acid sequences can be accessed through the NCBI Protein Database (accession numbers AAF33210 and NP_057517 for human GLTP; AAF33207, P17403, NP_786993 for bovine GLTP; AAF33208 and P17403 for porcine GLTP; and AAF33209 and Q9JL62 for mouse GLTP).
} 
the identical bovine and porcine GLTPs and has four conservative differences in amino acid composition $\left(\mathrm{K}^{10} \leftrightarrow \mathrm{R}^{10}, \mathrm{~A}^{65} \leftrightarrow \mathrm{T}^{65}, \mathrm{I}^{180} \leftrightarrow \mathrm{V}^{180}\right.$, and $\left.\mathrm{Q}^{200} \leftrightarrow \mathrm{R}^{200}\right)$.

\section{Preparation of Donor Vesicles}

Donor vesicles consisting of POPC and the fluorescent probes AV-GalCer and Per-PC, with or without the charged lipids, were prepared by the rapid ethanol injection technique $(25,26)$ and by extrusion approaches to obtain SUVs and LUVs, respectively. When using ethanol injection, POPC was mixed with $1 \mathrm{~mol} \% \mathrm{AV}-\mathrm{GalCer}$ and $1 \mathrm{~mol} \%$ Per-PC from stock solutions, dried under nitrogen and under vacuum for $1 \mathrm{~h}$, and redissolved immediately before use in absolute ethanol. The mixture $(5 \mu \mathrm{L}, 40 \mathrm{nmol})$ was rapidly injected with a $25-\mu \mathrm{L}$ Hamilton syringe into a $10 \mathrm{mM}$ sodium phosphate buffer ( $\mathrm{pH} 7.4$, containing $1 \mathrm{mM}$ dithiothreitol, $1 \mathrm{mM}$ EDTA, and $0.02 \%$ sodium azide) under rapid stirring at $37{ }^{\circ} \mathrm{C}$. The final concentration of the donor vesicles in the assay was $13 \mu \mathrm{M}$, and the ethanol concentration was less than $0.2 \%$. The final concentration of AV-GalCer in each assay was $0.13 \mu \mathrm{M}$. Previous studies have shown that galactocerebrosides are accommodated up to about $23 \mathrm{~mol} \%$ within PC vesicles without affecting vesicle stability (27). In our case, $1 \mathrm{~mol} \%$ of AV-GalCer was generally used in the donor vesicles.

Donor LUV vesicles of appropriate composition were prepared by extrusion through 100-nm size polycarbonate membranes. The appropriate amounts of lipids from the stock solutions were thoroughly mixed and dried first under nitrogen and second under vacuum for $1 \mathrm{~h}$. The dried lipid mixture was then hydrated in the appropriate buffer. Then, the dispersion was subjected to 15 freeze - thaw cycles to obtain a uniform distribution of buffer solutes across the bilayers. Rapid freezing was achieved by immersing the lipid suspension in an 2-propanol bath cooled by dry ice. During each thawing cycle, the lipid dispersion was raised above $70^{\circ}$ $\mathrm{C}$ and vortexed prior to subsequent refreezing. Each cycle of freezing, thawing, and vortexing took $3 \mathrm{~min}$, and the 15 total cycles took approximately $45 \mathrm{~min}$. The lipid suspension was then extruded by 21 passes through a 100-nm size polycarbonate membrane using a hand held miniextruder (Avanti). The resulting vesicles had a narrow size distribution $(28,29)$ and mean diameter of $100 \mathrm{~nm}$ as measured by gel-exclusion chromatography using a calibrated Sephacryl S-1000 column $(30,31)$.

\section{Preparation of Acceptor Vesicles}

The acceptor vesicles were prepared by sonication using a modification of the established procedure of Huang and Thompson (32). Briefly, a lipid film was obtained by slowly evaporating the appropriate mixture in solvents at $37^{\circ} \mathrm{C}$ on a rotary evaporator, followed by freeze drying in a vacuum for $6 \mathrm{~h}$. The dried lipid film was suspended by vortexing in a sodium phosphate buffer ( $\mathrm{pH} 7.4$ ) to a concentration of $50 \mathrm{mM}$. The suspension was sonicated with a Heat Systems-Ultrasonics W-225 sonifier on ice, under nitrogen, and was then centrifuged for $90 \mathrm{~min}$ at $100000 \mathrm{~g}$ to remove titanium probe particles, multilamellar vesicles, and undispersed lipid. Analysis of the resulting SUV populations by gel-exclusion chromatography confirmed average diameters of about $25 \mathrm{~nm}$, consistent with previously published values $(30,31)$.

\section{Activity of GLTP}

Two established assays involving either fluorescent or radiolabeled GalCer were used to assess GLTP activity. The fluorescence-based resonance energy transfer (RET) assay involved anthrylvinyl labeled glycolipid (AV-GalCer) $(1 \mathrm{~mol} \%)$ and a nontransferable perylenoyllabeled phosphatidylcholine (Per-PC) (1 mol \%), permitting continuous real-time monitoring of GLTP activity. The established nature of the RET assay is well-documented $(16,17,22,33)$. Briefly, the emission wavelengths of anthrylvinyl overlap with the excitation wavelengths of perylenoyl. Exciting the AV-GalCer at $370 \mathrm{~nm}$ resulted in the RET to the 
perylenoyl residue of phosphatidylcholine. Because of the close proximity of AV-GalCer and Per-PC in the donor vesicles, effective RET results in quenching of the AV-GalCer emission but not of the Per-PC emission. However, selective removal of AV-GalCer from the donors in the presence of GLTP and excess acceptors results in a decreased RET, and as a result, AVGalCer emission is observed at $425 \mathrm{~nm}$. The progression of transfer was followed by measuring the change in fluorescence emission at $425 \mathrm{~nm}$ relative to the baseline fluorescence in the absence of GLTP. The initial velocity $v_{0}$ and the maximum transfer $\Delta F_{\max }$ were calculated by fitting the relative change of fluorescence using the following equation:

$$
\frac{F^{425}(t)-F_{\mathrm{b} 1}^{425}}{F_{\mathrm{b} 1}^{425}}=\Delta F(t)=\Delta F_{\max }\left(1-e^{-\left(\frac{v_{0}}{\Delta F_{\max }} t\right)}\right)
$$

In this equation, $\mathrm{F}_{\mathrm{bl}}^{425}$ and $F^{425}$ are the emission intensity at $425 \mathrm{~nm}$ (excitation at $370 \mathrm{~nm}$ ) before and after the addition of GLTP, respectively (Figure 1). Nonlinear regression of the experimental data was performed using the ORIGIN 7.0 software (Origin Lab, Northhampton, $\mathrm{MA}$ ), and the standard deviations in the fitting were calculated at a 95\% confidence interval. $R^{2}$ values for all of the estimates were $>0.96$. Fluorescence emission of donor vesicles (POPC/ AV-GalCer/Per-PC; mol \% 98:1:1), excited at $370 \mathrm{~nm}$, did not vary significantly as a function of the temperature or as a function of the size of vesicles (data not shown). Initial velocity $v_{0}$ and maximum $\mathrm{AV}$-GalCer transferred $\Delta F_{\max }$ thus obtained were in relative fluorescence units. $v_{0}$ and $\Delta F_{\max }$ for AV-GalCer transfer at increasing GLTP concentrations were measured for SUV and LUV donors, with acceptors always being SUVs and present at 10- and 40-fold molar excess for SUV and LUV donors, respectively. Changing the acceptor-donor ratio in a range of 40:10 had no effect on the kinetics of transfer. All fluorescence measurements were performed using a SPEX Fluoromax instrument (Instruments S. A., Inc. Edina, NJ) equipped with a temperature programmable circulating water bath (Neslab RTE-111, Portsmouth, NH). The excitation and emission band passes were $5 \mathrm{~nm}$, and the cuvette holder was temperaturecontrolled to $\pm 0.1{ }^{\circ} \mathrm{C}$ at over the range of $30-44{ }^{\circ} \mathrm{C}$.

In the radiolabeled GalCer assay, donor vesicles are constructed so that they contain a negatively charged phospholipid and can be separated from neutral acceptor vesicles by ion exchange chromatography $(14,16,22)$. Sonicated POPC donor vesicles contained $1 \mathrm{~mol} \%$ [3H]-GalCer, $10 \mathrm{~mol} \%$ dipalmitoylphosphatidic acid, and a trace amount of nontransferable [14C]tripalmitate. Acceptor vesicles were sonicated with POPC SUVs. Each assay time point contained $13 \mu \mathrm{M}$ total lipid of donors, $400 \mu \mathrm{M}$ total lipid of acceptors, and transfer protein in a total volume of $3.0 \mathrm{~mL}$ of a sodium phosphate buffer $\mathrm{pH}$ 7.4. At desired time intervals, acceptor vesicles were separated from donor vesicles by rapid elution over DEAE Sephacel minicolumns $(1.8 \mathrm{~mL})$. Control experiments indicated typical acceptor recoveries between 70 and $80 \%$.

\section{RESULTS AND DISCUSSION}

\section{Kinetics of Intervesicular AV-GalCer Transfer}

The initial rate of AV-GalCer transfer, $v_{0}$, as a function of the GLTP bulk concentration at 37 ${ }^{\circ} \mathrm{C}$ and in the presence of 10 -fold excess of acceptor vesicles is shown in Figures 2A. It is evident that the initial velocities of glycolipid transfer from both SUVs and LUVs increase linearly over the GLTP concentration range of 0-141 nM. However, the initial transfer rates are strongly affected by membrane curvature and are significantly higher for SUV donors. The slopes of the linear fits of the data in Figure 2A reveal that GLTP initial transfer rates are more than 5 times greater for SUVs than for LUVs. A direct outcome of these results is that the mechanism of GLTP action in the presence of an excess of acceptor vesicles is first order with respect to the GLTP concentration. In Figure 2B, the amount of AV-GalCer transferred is 
expressed as the fraction of total accessible glycolipid $\left(\Delta F_{\max } / \Delta \mathrm{F}_{\max }^{\max }\right)$ in SUV ( $(\boldsymbol{)})$ and LUV $(\bullet)$ donors and is plotted as a function of the GLTP bulk concentration. $\Delta F_{\max }$ corresponds to the total amount of AV-GalCer transferred under the conditions of the assay. $\Delta F_{\max }^{\max }$ represents the total amount of glycolipid present in both the outer and inner leaflets of the donor vesicles. For both SUVs and LUVs, the $\Delta F_{\max } / \Delta \mathrm{F}_{\max }^{\max }$ values increase in single-exponential fashion, although the initial increase is greater for SUVs than LUVs. Even so, the $\Delta F_{\max } / \Delta \mathrm{F}_{\max }^{\max }$ values for SUVs attain lower values and level off at lower GLTP concentrations than those of LUVs (more explanation in the text below). It is reasonable to propose that each value of $\Delta F_{\max } / \Delta \mathrm{F}_{\max }^{\max }$ in Figure $2 \mathrm{~B}$ represents an equilibrium state at that particular concentration of GLTP. Then, it follows that $\Delta F_{\max } / \Delta \mathrm{F}_{\max }^{\max }$ reflects the $n e t$ steady-state transfer of GSL, i.e., the GSL equilibrium distribution existing among the acceptors, donors, and protein. Net mass transfer of GalCer has been previously reported for both pig and bovine brain $\operatorname{GLTP}(7,35)$. The data in Figure 2B also show that increasing amounts of GLTP in the assay lead to a saturation effect, resulting in a maximum value of $\Delta F_{\max } / \Delta \mathrm{F}_{\max }^{\max }\left(\Delta \mathrm{F}_{\max }^{\infty} \Delta \mathrm{F}_{\max }^{\max }\right) \cdot \Delta F_{\max }^{\infty}$ was measured by single-exponential fitting of the $\Delta F_{\max }$ data as a function of the increasing GLTP concentration. $R^{2}$ values for all of the fitted data is 0.99 at $95 \%$ CI. Because the GLTP concentrations that result in $\Delta F_{\max }^{\infty} / \Delta \mathrm{F}_{\max }^{\max }$ (Figure $2 \mathrm{~B}$ ) produce linear changes in the initial transfer velocity (Figure 2A), it is reasonable to attribute the saturation response to the rapid depletion of the accessible GSL pool in the donors by GLTP during transfer to the excess acceptors because GLTP does not traverse the membrane and can only access GSLs in the outer surface of the donor vesicles $(15,35-37)$. Thus, $\Delta F_{\max }^{\infty}$ reflects the AV-GalCer pool initially present in the outer leaflet of the donor vesicles. In LUVs, monohexosylceramides distribute uniformly $(\sim 1: 1)$ between the inner and outer leaflets of the POPC vesicle bilayer (38). Because $\Delta F_{\max }^{\infty}$ corresponds to the outer leaflet AV-GalCer in the LUV donors, the data are expressed as the fraction of total AV-GalCer present in the donor vesicles (Figure 2B). The maximum value of $\Delta F_{\max }\left(\Delta F_{\max }^{\max }\right)$ is calculated as twice the value of $\Delta F_{\max }^{\infty}$ for LUVs, consistent with the transbilayer distributions reported by Sillence et al. (38) for GlcCer derivatives in LUVs. The saturation value for LUV is half of the total calculated AV-GalCer pool $\left(\Delta F_{\max }^{\max }\right)$. For SUVs, however, the $\Delta F_{\max } / \Delta \mathrm{F}_{\max }^{\max }$ ratio reaches a saturation value of 0.36 , consistent with $36 \%$ of AV-GalCer being accessible and distributed in the outer leaflet of the donor vesicle. This value agrees well with the transbilayer distribution of GalCer in SUVs measured by ${ }^{13} \mathrm{C}$ NMR previously in our laboratory (39).

Because the steady-state value in the transfer curve of $\mathrm{AV}$-GalCer reflects equilibrium, the molar equivalent of $\Delta F_{\max }$ can be used to calculate the equilibrium constant between the donors and the acceptors. The molar equivalent of $\Delta F, \Delta F^{\mathrm{mol}}$, can be calculated by realizing that $\Delta F_{\max }^{\infty} / \Delta \mathrm{F}_{\max }^{\max }$ (the saturation value) corresponds to the fractional accessible pool of the GSL. For LUV, it is half of the total AV-GalCer originally present in the donor vesicles. Thus, $\Delta \mathrm{F}^{\mathrm{mol}}=(f \Delta F[\mathrm{AV}-\mathrm{GalCer}]) /\left(\Delta \mathrm{F}_{\max }^{\infty} / \Delta \mathrm{F}_{\max }^{\max }\right)$, where $f$ is 0.5 and 0.36 for LUV and SUV, respectively. Establishing the relationship between $\Delta F_{\max }^{\infty} / \Delta \mathrm{F}_{\max }^{\max }$ and GSL concentration available for transfer from the outer surfaces of LUVs and SUVs permits the kinetic data to be calculated in terms of the molar initial transfer rates (Figure 2A). To independently confirm the values in Figure 2A, a well-established radioisotope transfer assay was used to estimate transfer velocities of $1 \mathrm{~mol} \%[3 \mathrm{H}]-\mathrm{GalCer}$ from $\operatorname{SUV}(14,22)$. Values obtained from assays

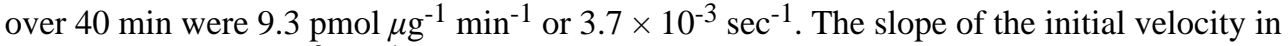
Figure $2 \mathrm{~A}$ is $4.9 \times 10^{-3} \mathrm{sec}^{-1}$, close to values obtained from the radioisotope assay. In the radioisotope assay, $10 \%$ dipalmitoyl phosphatidic acid (DPPA) is included in the donor vesicles to enable separation of acceptors by ion exchange chromatography. In a previous study, transfer of AV-GalCer from a charged vesicle by GLTP was shown to be slower than 
from uncharged vesicles (16). This may explain the lower value of transfer rates obtained for the radioisotope assay.

The net overall transfer of GSL from the donors to the acceptors is characterized by the total change in fluorescence $\left(\Delta F_{\max }\right)$. The total available AV-GalCer is characterized by the maximum possible change in fluorescence $\left(\Delta F_{\max }^{\infty}\right)$. Thus, the equilibrium constant for net transfer of AV-GalCer is represented as the ratio of AV-GalCer in the acceptors and donors. In equation form

$$
\begin{aligned}
& K_{\mathrm{eq}}^{D \leftrightarrow A}=\frac{[\mathrm{AV}-\mathrm{GalCer}]_{\mathrm{Acc}} /[\mathrm{Acc}]}{[\mathrm{AV}-\mathrm{GalCer}]_{\mathrm{Don}} /[\mathrm{Don}]} \approx \frac{\Phi \Delta F_{\max }^{\mathrm{mol}}}{\left(\Delta F_{\max }^{\infty \mathrm{mal}}-\Delta F_{\max }^{\mathrm{mol}}\right)} \approx \\
& \frac{\Phi \Delta F_{\max }^{\operatorname{mol}} / \Delta F_{\max }^{\infty}}{\left(1-\Delta F_{\max }^{\operatorname{mol}} / \Delta F_{\max }^{\infty}\right)}
\end{aligned}
$$

$\Phi$ is the area ratio of donors/acceptors in the assay and is 0.1 under experimental conditions. [Acc] and [Don] are the lipid molar concentrations of the acceptors and the donors, respectively. To obtain an accurate measure of $\mathrm{K}_{\mathrm{eq}}^{\mathrm{D} \leftrightarrow \mathrm{A}}$, the operational ratio of donors/protein should be below the limit corresponding to $\Delta F^{\infty}{ }_{\text {max }}$. In our experiments, this requirement was achieved by having the protein concentration at 14 and $28 \mathrm{nM}$ for SUV and LUV donors, which both were present at $13.3 \mu \mathrm{M}$ lipid concentration along with SUV acceptors at 133 and $532 \mu \mathrm{M}$ lipid concentration, respectively. At bulk protein concentrations higher than the working range, the measurement of overall transfer is limited by the amount of AV-GalCer in the vesicle outer leaflets.

\section{GLTP Action and Associated Kinetic Parameters}

There are three distinct mechanisms that can be considered for GLTP action. One possibility is that GLTP forms a conduit between the donors and acceptors, allowing the exchange of GSL between the two (Figure 3A). This "conduit" mechanism would necessitate the formation of aggregates containing donors, acceptors, and protein. Previously, we investigated this possibility using right-angle light scattering (see Figure 6 in ref 33) and found no evidence of vesicle aggregation/fusion upon addition of GLTP, suggesting that the mechanism represented in Figure 3A is unlikely.

Two other mechanisms can be envisioned in which GLTP mediates no contacts between vesicles but instead facilitates desorption of glycolipid from the donor vesicle surface. The fundamental difference between the two mechanisms is whether GLTP mediates transfer by lowering the energy barrier for selective glycolipid desorption while remaining bound to the donor vesicle or whether GLTP and glycolipid form a complex that then desorbs from the donor vesicle surface to accomplish transfer. A schematic of the first variation where the protein remains bound to the donor surface (bound transporter) is presented in Figure 3B. In this model, the soluble GLTP $\left(\mathrm{P}_{\mathrm{B}}\right)$ adsorbs to the donor vesicle surface $\left(\mathrm{P}_{\mathrm{D}}\right)$ where it forms an activated complex $\left(\mathrm{P}_{\mathrm{D}} \mathrm{L}_{\mathrm{D}}^{\ddagger}\right)$ with the glycosphingolipid. Once the activated complex is formed, because of its high-energy state, the glycolipid is ejected into the bulk aqueous phase $\left(\mathrm{L}_{\mathrm{B}}\right)$ where it is free to readsorb to any nearby vesicle (donor or acceptor) that is encountered. The protein reverts to its nonactivated state and again forms a complex with the remaining substrate. In the alternative model, the activated complex itself releases into the bulk (free transporter) as shown in the schematic presented in Figure 3C. A complete solution to the models described in parts $\mathrm{B}$ and $\mathrm{C}$ of Figure 3 is presented in Appendix A. The final solution to the model can be written in its mathematical form as follows:

$$
v_{0}=\frac{k_{+3} k_{+1} \Gamma_{\mathrm{L}_{\mathrm{D}}}}{k_{-1} K_{\mathrm{M}}^{\mathrm{D}}+k_{+3} \Gamma_{\mathrm{L}_{\mathrm{D}}}}\left[\mathrm{P}_{\mathrm{B}}\right]
$$


In this equation, $v_{0}$ is the initial transfer velocity, $\mathrm{P}_{\mathrm{B}}$ is the bulk concentration of GLTP, $\Gamma_{L_{D}}$ is the surface concentration of the GSL, $k_{+3}$ is the desorption constant of the $\mathrm{P}_{\mathrm{D}} \mathrm{L}_{\mathrm{D}}^{\ddagger}$ complex, $k_{+1}$ is the adsorption constant of $\mathrm{P}_{\mathrm{B}}$ to the donor, $k_{-1}$ is the desorption constant of GLTP $\left(\mathrm{P}_{\mathrm{D}}\right)$ from the donors, and $K_{\mathrm{M}}^{\mathrm{D}}$ is the two-dimensional Michalis-Menten-type constant for the GLTP - GSL complex at the donor surface $\left(\mathrm{P}_{\mathrm{D}} \mathrm{L}_{\mathrm{D}}^{\ddagger}\right)$. Even for the most simplistic models, the initial velocity of transfer $v_{0}$ is a complex combination of kinetic rate constants as shown in eq 2 . Under a hypothetical situation, where the GSL surface concentration $\left(\Gamma_{L_{D}}\right)$ is in excess such that $\mathrm{K}_{\mathrm{M}}^{\mathrm{D}} \ll \Gamma_{\mathrm{L}_{\mathrm{D}}}$ is satisfied and desorption constants $k_{+3}$ and $k_{-1}$ are comparable, eq 2 can be simplified as follows:

$$
v_{0} \approx k_{+1}\left[\mathrm{P}_{\mathrm{B}}\right]
$$

In the event that $\Gamma_{\mathrm{L}_{\mathrm{D}}}$ is not in excess, $k_{+3}$ and $k_{-1}$ are comparable, and $\mathrm{K}_{\mathrm{M}}^{\mathrm{D}} \gg \Gamma_{\mathrm{L}_{\mathrm{D}}}$, eq 2 can be simplified as

$$
v_{0} \approx \frac{k_{+3} k_{+1}}{k_{-1} K_{\mathrm{M}}^{\mathrm{D}}}\left[\mathrm{P}_{\mathrm{B}}\right] \Gamma_{\mathrm{L}_{\mathrm{D}}}
$$

In either case, the initial velocity is first order with respect to the bulk concentration of $\mathrm{P}_{\mathrm{B}}$, as observed in our experiments (see Figure 2A). It is evident from eqs 3 and 4 that interpretation of $v_{0}$ in terms of kinetic constants depends on the system parameters, particularly the relative values of $K_{\mathrm{M}}^{\mathrm{D}}$ and $\Gamma_{\mathrm{L}_{\mathrm{D}}}$. For instance, in the case that $\Gamma_{\mathrm{L}_{\mathrm{D}}}$ is in excess and $k_{+3}$ and $k_{-1}$ are comparable, $v_{0}$ is simply related to the adsorption rate constant of $\mathrm{P}_{\mathrm{B}}$ (eq 3). On the other hand, when $\mathrm{K}_{\mathrm{M}}^{\mathrm{D}} \gg \Gamma_{\mathrm{S}_{\mathrm{D}}}, v_{0}$ is first order with respect to the substrate concentration and is related to the binding constant of $\mathrm{P}_{\mathrm{B}}$ to the donor and the desorption rate of the $\mathrm{P}_{\mathrm{D}} \mathrm{L}_{\mathrm{D}}^{\ddagger}$ complex (eq 4). In this situation, the two-dimensional surface processes (surface diffusion of protein and substrate) leading to the $\mathrm{P}_{\mathrm{D}} \mathrm{L}_{\mathrm{D}}^{\ddagger}$ complex become important. Because $1 \mathrm{~mol} \% \mathrm{AV}$-GalCer was used in our experiments, it is more likely that eq 4 is valid and that the $P_{D} L_{D}^{\ddagger}$ complex formation mechanism operates under the limiting $\Gamma_{\mathrm{L}_{\mathrm{D}}}$ condition.

Because the equations governing the bound transporter and free transporter mechanisms converge, these two schemes cannot be distinguished based solely on the initial velocity measurements. However, consideration of the relative amounts of donor and acceptor vesicles provides additional insights that are important for distinguishing the mechanisms. Under the free transporter mechanism, the overall transfer of AV-GalCer occurs by GLTP acting as a shuttle that acquires AV-GalCer from donor vesicles and unloads it into acceptor vesicle bilayers. The net transfer is driven by the starting glycolipid concentration difference between the donors and acceptors, which are initially devoid of glycolipid, as well as the excess of acceptor vesicles. Under the bound transporter mechanism, the overall transfer of GSL occurs by GLTP remaining bound to the vesicles while ejecting AV-GalCer into the bulk aqueous phase. The AV-GalCer in the bulk is then free to readsorb to either the donor or acceptor vesicles. If the bound transporter mechanism is responsible for GLTP action, then the maximum change in fluorescence, $\Delta F_{\max }$, should increase proportionally to the increase in the initial number of donors in the assay because the bound GLTP completely exhausts the donor surface. On the other hand, if the free transporter mechanism is operational, then $\Delta F_{\max }$ should not increase proportionally to the number of donors in the assay. To distinguish between the bound transporter and free transporter mechanisms, $\Delta F_{\max }$ values were measured as a function of the initial amounts of donor lipid while keeping the acceptor amount constant (Figure 4). The acceptor-donor ratio did not have a significant effect on $\Delta F_{\max }$. From the results in Figure 4 , it is evident that increasing the donor concentration as high as 4-fold did not result in a proportional increase in the $\Delta F_{\max }$ values. These data strongly suggest that the free 
transporter mechanism is the operational mechanism for GLTP under the experimental conditions. To reiterate the point made earlier, in the case of the bound transporter mechanism, increasing the donor vesicle concentration should have resulted in a proportional increase in the values of $\Delta F_{\max }$, and clearly, that was not the case. Thus, the kinetic parameters are consistent with GLTP acting as a freely transporting shuttle, carrying GSL back and forth between the donor and acceptor vesicles.

\section{Rate-Limiting Step in GLTP-Mediated Transfer}

If binding of GLTP to the donor membrane is rate-limiting, then increasing the number of donors in the assay should increase $v_{0}$ because of the increased binding sites. Figure 4 shows the response of $v_{0}$ to different initial donor concentrations. There is no increase in $v_{0}$ over a 4 fold change in the donor concentration, clearly suggesting that binding of GLTP to the donor membrane is not the rate-limiting step. On the other hand, increases in the GLTP concentration lead to proportional increases in $v_{0}$ (Figure $2 \mathrm{~A}$ ). Thus, the events occurring on the donor surface and involving the GLTP-GSL complex formation and release from the surface are likely to constitute the rate-limiting step.

\section{GLTP Action and Associated Thermodynamic Parameters}

The mechanism of action used by GLTP to transfer AV-GalCer between donor and acceptor vesicles is a multistep process, wherein protein-lipid interactions are expected to be of paramount importance. Spontaneous transfer of AV-GalCer is known to be extremely slow, with a half-life of days $(33,34)$. Over the time course of our experiments, there is an insignificant transfer of AV-GalCer between the donors and acceptors (10-fold excess) in the absence of GLTP, consistent with a high-energy barrier associated with the removal of AV-GalCer from the donor vesicles. The energy requirements that govern the overall GLTP-mediated transfer process were characterized by analyzing the effect of temperature change on the transfer rate constants and equilibrium constants, i.e., Arrhenius and van't Hoff plots, respectively.

Arrhenius plots of the GLTP-mediated molar initial transfer rates $v_{0}$ as a function of the temperature are presented for SUVs and LUVs in Figure 5A. The plots are linear over the experimental temperature range for both types of vesicles. Because the vesicles were composed of $98 \mathrm{~mol} \%$ POPC, no phase transition occurs within the experimental temperature range and the vesicles exist in the $\mathrm{L}_{\alpha}$ phase state (liquid crystalline phase). The minimum activation energy for the overall GLTP-mediated transfer process was obtained using Arrhenius plots. Calculation of the activation energies from the linear Arrhenius responses revealed larger activation energy for LUVs $\left(25.1 \pm 1.1 \mathrm{kcal} \mathrm{mol}^{-1}\right.$ or $\left.104.9 \pm 4.3 \mathrm{~kJ} \mathrm{~mol}^{-1}\right)$ than for SUVs $(21.7$ $\pm 0.4 \mathrm{kcal} \mathrm{mol}^{-1}$ or $90.9 \pm 1.6 \mathrm{~kJ} \mathrm{~mol}^{-1}$ ). Using the absolute rate theory, other thermodynamic parameters were calculated from the activation energy (Table 1). The transition-state values are similar to values obtained for the transfer of phospholipids between SUVs mediated by phospholipid transfer protein (40).

The effect of changing temperature on the overall GSL transfer equilibrium, i.e., $\mathrm{K}_{\mathrm{eq}}^{\mathrm{D} \leftrightarrow \mathrm{A}}$, was calculated as described earlier (eq 1) and analyzed using van't Hoff plots (Figure 5B) for the systems involving LUV and SUV donor vesicles. The plots are linear for both vesicle systems, permitting the calculation of the enthalpy $\left(\Delta H_{\mathrm{eq}}\right)$ of overall transfer from the reciprocal of the slopes. There is no significant difference between the enthalpy of overall transfer of GSL for LUV and SUV $\left(15 \mathrm{kcal} \mathrm{mol}^{-1}\right.$ or $\left.63 \mathrm{~kJ} \mathrm{~mol}^{-1}\right) . \Delta G_{\mathrm{eq}}$ is much lower (12\%) than $\Delta H_{\mathrm{eq}}$. Evidently, the entropic contributions dominate the net transfer of GSL. This situation probably results from the dominant role played by hydrophobic effects in determining the net transfer. A net transfer occurs because GSL is present initially only on the donor vesicles and there is an excess of acceptor vesicles. This situation mimics the cellular environment where the local membrane concentration for glycolipids is likely to be high. 
The thermodynamic parameters for the transition state, $\Delta H^{\ddagger}, \Delta G^{\ddagger}$, and $\Delta S^{\ddagger}$ are shown in Table 1. For SUV, $\Delta H^{\ddagger}$, is less than but a major contributor (99\%) to $\Delta G^{\ddagger}$. For LUV, however, $\Delta H^{\ddagger}$ is greater than but still a major contributor (109\%) to $\Delta G^{\ddagger}$. A similar response but only for SUVs has been reported for phospholipid transfer protein (40). For GLTP, the major difference in $\Delta H^{\ddagger}$ for SUVs and LUVs is compensated by entropic $\left(\Delta S^{\ddagger}\right)$ contributions resulting in similar values of $\Delta G^{\ddagger}$. This enthalpy—entropy compensation is attributed to GLTP binding to the membrane $(41,42) . \Delta H^{\ddagger}$ values for the GLTP_GSL complexation were found to be endothermic for both SUVs and LUVs. These high endothermic values for the GLTP_GSL complex are due to the contributions of complex formation at the surface. Moreover, the difference between $\Delta H^{\ddagger}$ for SUVs and LUVs is small $\left(14 \mathrm{~kJ} \mathrm{~mol}^{-1}\right.$ or $\left.3.4 \mathrm{kcal} \mathrm{mol}^{-1}\right)$ and can be attributed to the effects of curvature on GLTP-membrane binding. The major contributors to the endothermic $\Delta H^{\ddagger}$, i.e., steps involved in the GLTP—GSL formation at the surface, would have similar energetics for both SUVs and LUVs. This also provides additional evidence for the GLTP-GSL complex formation as being the rate-limiting step. The endothermic nature of $\Delta H^{*}$ associated with the GLTP-GSL complex formation is noteworthy because stable, long-term binding of noncatalytic peptides to membranes is often found to be an exothermic process $(41,42)$. In this regard, the thermodynamic data provide additional evidence of GLTP associating transiently with the membrane, as would be expected for a shuttle/carrier mechanism of action.

\section{Implications}

To our knowledge, this study represents the first systematic modeling of GLTP interaction with SUVs and LUVs. The model is novel in its treatment of GLTP action as a multistep process occurring at the membrane interfacial region and requiring interaction with glycolipid. The model also provides a potentially valuable tool for better understanding the capacity of GLTP to probe the physicochemical features of membranes enriched in glycosphingolipids, i.e., rafts. While other models have been developed for various phospholipid transfer proteins (43-47), these models traditionally rely on ordinary two-substrate enzymecatalyzed reactions that can be adequately described by ping-pong Bi-Bi mechanisms. The models are well-suited for characterizing transfer mechanisms involving single-component lipid membranes, as is the case for phosphatidylcholine transfer protein (46). However, for cases such as those investigated here, a minor lipid component (e.g., AV-GalCer) is being transferred from a twocomponent lipid membrane in which the major lipid component (POPC) serves as a matrix and is not a "substrate" for the lipid transfer protein. This situation is more similar but not identical to that of the phosphatidylinositol transfer protein (PITP), which displays about a 15fold preference for PI over PC. In previous modeling studies of PITP action $(46,48)$, it was assumed that the initial transfer velocity can be described solely in terms of donor and acceptor vesicle concentrations to model the functional unit of interaction with PITP. While this assumption may hold when PI concentrations are relatively high in the membrane vesicles, the situation becomes more complicated in cases where the minor lipid component is present at low concentrations in the membrane (e.g., $<10 \mathrm{~mol} \%$ ). Under such conditions, the "substrate" lipid concentration within individual vesicles can be expected to be of paramount importance because LTP adsorption to a membrane vesicle may not be kinetically synonymous with the formation of a complex between LTP and its substrate lipid. In other words, at low glycolipid concentrations, a situation typical for many biomembranes, formation of the GLTP-GSL complex within the membrane interfacial environment may require lateral diffusion of either GSL, GLTP, or both. Also kept in mind while developing our experimental strategies and mathematical formalism for modeling GLTP-mediated transfer of GSLs between membrane vesicles were the reported nonrandom lateral organization of GSLs in biomembranes, i.e., rafts, and the tendency of GSLs to localize in both planar and curved regions of biomembranes, i.e., caveolae. 
Our comprehensive characterization of the GLTP-mediated transfer of the minor component GSLs from curved and planar model membranes has included assessment of the energy requirements for achieving both an activated state and for a net overall transfer. The analyses, based on the contributions of various kinetic steps and the overall energy requirements, suggest that (a) GLTP acts as a freely transporting shuttle, carrying GSL back and forth between the donor and the acceptor vesicles, and (b) the rate-limiting step for GLTP action is the GLTPGSL complex formation at the membrane surface and not the binding to the donor vesicle. Differences in GLTP binding to LUVs and SUVs appear to explain the observed differences in GLTP-mediated GSL transfer for these two systems, a possibility supported by preliminary fluorescence energy transfer experiments in which GLTP intrinsic fluorescence is used to follow binding to LUVs and SUVs containing dansylated lipid (49). Also noteworthy is the observation that the binding of free GLTP to the membrane appears to have a minimal contribution to the overall $\Delta H^{\ddagger}$ and $\Delta G^{\ddagger}$ of the system. A direct implication of these findings is that GLTP action is likely to be influenced by surface processes that affect formation and release of the GLTP - GSL complex. Thus, processes that influence this step, like GSL compartmentalization or domain formation, can be studied using GLTP-membrane systems.

In the present study, we have demonstrated that surface processes, which depend on the microenvironments of the substrate and that lead to the formation and release of the GLTPGSL complex, dominated the transfer mechanism. We also have presented and mathematically solved a model for GLTP action that can be potentially used to probe GSL-containing membranes. The tools developed in this study are likely to provide new ways to analyze GSL environments in biological membranes containing lipid rafts.

\section{ACKNOWLEDGMENT}

We are grateful to Drs. Taeowan Chung and Margarita Malakhova for their advice and help in subcloning and optimizing expression conditions for the recombinant human GLTP and to Dr. Peter Mattjus for helpful discussions and for sharing unpublished data.

\section{APPENDIX A \\ Mathematical Description of Initial Velocity of GLTP Activity Based on the Proposed Mechanism}

There are two basic assumptions involved with the mechanisms proposed in parts $\mathrm{B}$ and $\mathrm{C}$ of Figure 3. First, the protein has to adsorb from the solution to the donor interface, and second, there is a formation of the activated complex that is essential for the release of either glycolipid (bound transporter) or the glycolipid-protein (free transporter) complex. Evidence of complex formation of GLTP with GSL has been previously demonstrated by fluorescence $(7,50)$ and radioactive methods $(9,11)$. However, the details of GLTP-GSL interactions are largely unknown. Implicit in the formation of an activated-state complex $P_{D} L^{\ddagger}$ is the assumption that the residence time of the complex would be very small. As a result, a quasisteady-state (qss) approximation is valid for the activated-complex concentration. The following equations may be written for the mass balance of $\mathrm{P}_{\mathrm{D}} \mathrm{L}^{\ddagger}$ for either of the mechanisms:

$$
\begin{aligned}
& 0=\frac{\mathrm{d} \Gamma_{\mathrm{P}_{\mathrm{D}} \mathrm{L}_{\mathrm{D}}^{*}}}{\mathrm{~d}}=k_{+2} \Gamma_{\mathrm{P}_{\mathrm{D}}} \Gamma_{\mathrm{L}_{\mathrm{D}}}- \\
& \left(k_{-2}+k_{+3}^{\prime}\right) \Gamma_{\mathrm{P}_{\mathrm{D}} \mathrm{D}_{\mathrm{D}}^{*}}+k_{-3}^{\prime}\left[\mathrm{L}_{\mathrm{B}}\right] \frac{V_{\mathrm{L}}}{n_{\mathrm{D}} A_{\mathrm{s}}} \\
& 0=\frac{\mathrm{d} \quad \Gamma_{\mathrm{P}_{\mathrm{D}} \mathrm{L}_{\mathrm{D}}^{*}}^{t}}{t}=k_{+2} \Gamma_{\mathrm{P}_{\mathrm{D}}} \Gamma_{\mathrm{L}_{\mathrm{D}}}- \\
& \left(k_{-2}+k_{+3}\right) \Gamma_{\mathrm{P}_{\mathrm{D}} \mathrm{L}_{\mathrm{D}}^{+}}+k_{-3}\left[\mathrm{P}_{\mathrm{B}} \mathrm{L}_{\mathrm{B}}\right] \frac{V_{\mathrm{L}}}{n_{\mathrm{D}} A_{s}}
\end{aligned}
$$


In these equations, all of the $\Gamma$ values are the interfacial concentrations of the respective species. $V_{\mathrm{L}}$ is volume of the bulk, $n_{\mathrm{D}}$ is the number of donor vesicles, and $A_{\mathrm{s}}$ is the surface area of donor vesicles. The factor $V_{\mathrm{L}} / n_{\mathrm{D}} A_{\mathrm{S}}$ denotes the bulk concentration seen from the donor surface. When the acceptor population is in a large excess of the donor population (10-fold excess in surface area), the initial rate of readsorption of $\mathrm{L}_{\mathrm{B}}$ or the $\mathrm{P}_{\mathrm{B}} \mathrm{L}_{\mathrm{B}}$ complex to the donor can be considered negligible compared to its readsorption to the acceptor. In our assay, the acceptor vesicle surface areas for both SUVs and LUVs are in an excess of the donor population and hence such a condition is established. Thus, the eqs $\mathrm{A} 1 \mathrm{a}$ and $\mathrm{A} 1 \mathrm{~b}$ tend to be similar under the assumption that initial rate of readsorption of $\mathrm{P}_{\mathrm{B}}$ or the $\mathrm{P}_{\mathrm{B}} \mathrm{L}_{\mathrm{B}}$ complex from the bulk to the donor is negligible. The only difference would be the differences in definitions of $k_{+3}\left(\mathrm{k}^{\prime}+3\right)$ and $k_{-3}$ $\left(\mathrm{k}_{-3}\right)$. Henceforth, for convenience, only one notation that of $k_{+3}$ and $k_{-3}$ will be used. Under these conditions, it is not possible to distinguish between the two mechanisms because their governing equations tend to be the same

$$
\Gamma_{\mathrm{P}_{\mathrm{D}} \mathrm{L}_{\mathrm{D}}^{\frac{1}{j}}}=\frac{k_{+2} \Gamma_{\mathrm{P}_{\mathrm{D}}} \Gamma_{\mathrm{L}_{\mathrm{D}}}}{\left(k_{-3}+k_{+3}\right)}
$$

Similarly, writing the mole balance equation for $\mathrm{P}_{\mathrm{D}}$ on the donor surface

$$
\Gamma_{\mathrm{P}_{\mathrm{D}}}=\frac{\left(k_{-2}+k_{+3}\right)}{\left(k_{+2} \Gamma_{\mathrm{L}_{\mathrm{D}}}+k_{-2}+K_{+3}\right)} \Gamma_{\mathrm{P}_{\mathrm{Dtot}}}
$$

The initial velocity of transfer mediated by GLTP in molar units can be written as

$$
v_{0}=\frac{n_{D} A_{S}}{V_{L}} k_{+3} \Gamma_{\mathrm{P}_{\mathrm{D}} \mathrm{L}_{\mathrm{D}}^{*}}
$$

Using the qss assumption for the $\mathrm{P}_{\mathrm{D}} \mathrm{L}_{\mathrm{D}}^{\ddagger}$ complex

$$
v_{0}=\frac{n_{\mathrm{D}} A_{\mathrm{S}}}{V_{\mathrm{L}}} \frac{k_{+3} k_{+2}}{\left(k_{-2}+k_{+3}\right)} \Gamma_{\mathrm{P}_{\mathrm{D}}} \Gamma_{\mathrm{L}_{\mathrm{D}}}
$$

Substituting the appropriate value for the surface concentration of $\mathrm{P}_{\mathrm{D}}$

$$
\begin{gathered}
v_{0}=\frac{n_{\mathrm{D}} A_{\mathrm{S}}}{V_{\mathrm{L}}} \frac{k_{+3} k_{+2}}{\left(k_{-2}+k_{+3}\right)} \frac{\left(k_{-2}+k_{+3}\right)}{\left(k_{+2} \Gamma_{\mathrm{L}_{\mathrm{D}}}+k_{-2}+k_{+3}\right)} \Gamma_{\mathrm{P}_{\mathrm{Dtot}}} \Gamma_{\mathrm{L}_{\mathrm{D}}} \\
v_{0}=\frac{n_{\mathrm{D}} A_{\mathrm{S}}}{V_{\mathrm{L}}} \frac{k_{+3}}{\left(\Gamma_{\mathrm{L}_{\mathrm{D}}}+\frac{k_{-2}+k_{+3}}{k_{+2}}\right)} \Gamma_{\mathrm{P}_{\mathrm{Dtot}}} \Gamma_{\mathrm{L}_{\mathrm{D}}}
\end{gathered}
$$

Defining the Michalis-Menten-type constant for the $\mathrm{P}_{\mathrm{D}} \mathrm{L}^{\ddagger} \mathrm{D}$ complex formed on the donor vesicles

$$
K_{\mathrm{M}}^{\mathrm{D}}=\frac{k_{-2}+k_{+3}}{k_{+2}}
$$

Thus, the initial velocity for glycolipid transfer from the donor vesicles under the conditions where the acceptors are in excess may be written as

$$
v_{0}=\frac{n_{D} A_{S}}{V_{\mathrm{L}}} \frac{k_{+3}}{\left(\Gamma_{\mathrm{L}_{\mathrm{D}}}+K_{\mathrm{M}}^{\mathrm{D}}\right)} \Gamma_{\mathrm{P}_{\mathrm{Dtot}}} \Gamma_{\mathrm{L}_{\mathrm{D}}}
$$

This mathematical description of the initial velocity of transfer of glycolipid is a function of the surface concentration of GLTP and glycolipid. To obtain a tangible dependence of $v_{0}$ on the initial concentration of GLTP in the bulk, some understanding of the initial GLTP adsorption to the donor surface needs to be obtained. 


\section{GLTP Adsorption to the Donor Vesicle Surface}

From our basic assumption of the model, the initial adsorption of GLTP is essential for its transfer activity. The adsorption of GLTP is modeled by treating the interface as a black box, and thus, the only relevant events are the adsorption and desorption of protein species. The effect of surface processes is confounded in the equation by the concentrations of $\mathrm{P}_{\mathrm{D}}$ and

$\mathrm{P}_{\mathrm{D}} \mathrm{L}_{\mathrm{D}}^{\ddagger}$

$$
\frac{\mathrm{d} \quad \Gamma_{\mathrm{P}_{\mathrm{D} \text { tot }}}}{\mathrm{d} \quad t}=\frac{V_{\mathrm{L}}}{n_{\mathrm{D}} A_{\mathrm{S}}} k_{+1}\left[\mathrm{P}_{\mathrm{B}}\right]-k_{-1} \Gamma_{\mathrm{P}_{\mathrm{D}}}-k_{+3} \Gamma_{\mathrm{P}_{\mathrm{D}} L_{\mathrm{D}}^{*}}
$$

From an earlier assumption of qss for the $\mathrm{P}_{\mathrm{D}} \mathrm{L}_{\mathrm{D}}^{\ddagger}$ complex, substituting the values for $\Gamma_{\mathrm{P}_{\mathrm{D}}}$ and $\Gamma_{\mathrm{P}_{\mathrm{D}} \mathrm{L}_{\mathrm{D}}^{\ddagger}}$ Lqin eq A10

$$
\begin{gathered}
0=\frac{\mathrm{d} \frac{\Gamma_{\mathrm{P}_{\text {Dtot }}}}{\mathrm{d}}=\frac{V_{\mathrm{L}}}{n_{\mathrm{D}} A_{\mathrm{s}}} k_{+1}\left[\mathrm{P}_{\mathrm{B}}\right]-}{\frac{k_{-1}\left(k_{-2}+k_{+3}\right)+k_{+3} k_{+2} \Gamma_{\mathrm{L}_{\mathrm{D}}}}{k_{+2}\left(\Gamma_{\mathrm{L}_{\mathrm{D}}}+K_{\mathrm{M}}^{\mathrm{D}}\right)} \Gamma_{\mathrm{P}_{\mathrm{Dtot}}}} \\
\frac{V_{\mathrm{L}}}{n_{\mathrm{D}} A_{\mathrm{S}}} k_{+1}\left[\mathrm{P}_{\mathrm{B}}\right]=\frac{k_{-1} K_{\mathrm{M}}^{\mathrm{D}}+k_{+3} \Gamma_{\mathrm{L}_{\mathrm{D}}}}{\left(\Gamma_{\mathrm{L}_{\mathrm{D}}}+K_{\mathrm{M}}^{\mathrm{D}}\right)} \Gamma_{\mathrm{P}_{\mathrm{D} t o t}}
\end{gathered}
$$

From eq A12

$$
\Gamma_{\mathrm{P}_{\mathrm{D} \text { tot }}}=\frac{V_{\mathrm{L}}}{n_{\mathrm{D}} A_{\mathrm{S}}}\left[\frac{k_{+1}\left(\Gamma_{\mathrm{L}_{\mathrm{D}}}+K_{\mathrm{M}}^{\mathrm{D}}\right)}{k_{-1} K_{\mathrm{M}}^{\mathrm{D}}+k_{+3} \Gamma_{\mathrm{L}_{\mathrm{D}}}}\right]\left[\mathrm{P}_{\mathrm{B}}\right]
$$

Rewriting eq A9 using the profile of enzyme adsorption from eq A13

$$
v_{0}=\frac{k_{+3} k_{+1}}{k_{-1} K_{\mathrm{M}}^{\mathrm{D}}+k_{+3} \Gamma_{\mathrm{L}_{\mathrm{D}}}}\left[\mathrm{P}_{\mathrm{B}}\right] \Gamma_{\mathrm{L}_{\mathrm{D}}}
$$

Under the conditions where the surface concentration of glycolipid is in an excess such that $\mathrm{K}_{\mathrm{M}}^{\mathrm{D}} \ll \Gamma_{\mathrm{L}_{\mathrm{D}}}$ is satisfied and the desorption constants are comparable, eq A14 can be simplified as follows:

$$
v_{0} \approx k_{+1}\left[\mathrm{P}_{\mathrm{B}}\right]
$$

In the event that the surface concentration of glycolipid is not in excess, $\mathrm{K}_{\mathrm{M}}^{\mathrm{D}} \gg \Gamma_{\mathrm{L}_{\mathrm{D}}}$, and desorption constants are comparable, eq A14 can be simplified as

$$
v_{0} \approx \frac{k_{+3} k_{+1}}{k_{-1} K_{\mathrm{M}}^{\mathrm{D}}}\left[\mathrm{P}_{\mathrm{B}}\right] \Gamma_{\mathrm{L}_{\mathrm{D}}}
$$

In either case, the initial velocity of GLTP-mediated transfer is first order with respect to the bulk concentration of GLTP and can be described mathematically by eqs A14-A16.

\section{REFERENCES}

1. Kakugawa Y, Wada T, Yamaguchi K, Yamanami H, Ouchi K, Sato I, Miyagi T. Up-regulation of plasma membrane-associated ganglioside sialidase (Neu3) in human colon cancer and its involvement in apoptosis suppression. Proc. Natl. Acad. Sci. U.S.A 2002;99:10718-10723. [PubMed: 12149448]

2. Nakajima H, Kiyokawa N, Katagiri YU, Taguchi T, Suzuki T, Sekino T, Mimori K, Ebata T, Saito M, Nakao H, Takeda T, Fujimoto J. Kinetic analysis of binding between Shiga toxin and receptor 
glycolipid Gb3Cer by surface plasmon resonance. J. Biol. Chem 2001;276:42915-42922. [PubMed: 11557760]

3. Dumoulin F, Lafont D, Boullanger P, Mackenzie G, Mehl GH, Goodby JW. Self-organizing properties of natural and related synthetic glycolipids. J. Am. Chem. Soc 2002;124:13737-13748. [PubMed: 12431104]

4. Brown DA, London E. Functions of lipid rafts in biological membranes. Annu. ReV. Cell DeV. Biol 1998;14:111-136. [PubMed: 9891780]

5. Metz RJ, Radin NS. Glucosylceramide uptake protein from spleen cytosol. J. Biol. Chem 1980;255:4463-4467. [PubMed: 7372587]

6. Metz RJ, Radin NS. Purification and properties of a cerebroside transfer protein. J. Biol. Chem 1982;257:12901-12907. [PubMed: 7130186]

7. Brown RE, Stephenson FA, Markello T, Barenholz Y, Thompson TE. Properties of a specific glycolipid transfer protein from bovine brain. Chem. Phys. Lipids 1985;38:79-93. [PubMed: 4064225]

8. Bankaitis, VA.; Fry, MR.; Cartee, RT.; Kagiwada, S. Phospholipid Transfer Proteins: Emerging Roles in Vesicle Trafficking, Signal Transduction, and Metabolic Regulation. Landes Bioscience; Austin, TX: 1996. p. 51-72.

9. Sasaki T. Glycolipid-binding proteins. Chem. Phys. Lipids 1985;38:63-77. [PubMed: 4064224]

10. Sasaki T. Glycolipid transfer protein and intracellular traffic of glucosylceramide. Experientia 1990;46:611-616. [PubMed: 2193825]

11. Abe A, Sasaki T. Purification and some properties of the glycolipid transfer protein from pig brain. J. Biol. Chem 1985;260:11231-11239. [PubMed: 4030789]

12. Yamada K, Abe A, Sasaki T. Specificity of the glycolipid transfer protein from pig brain. J. Biol. Chem 1985;260:4615-4621. [PubMed: 3988728]

13. Yamada K, Abe A, Sasaki T. Glycolipid transfer protein from pig brain transfers glycolipids with $\beta$ linked sugars but not with R-linked sugars at the sugar-lipid linkage. Biochim. Biophys. Acta 1986;879:345-349. [PubMed: 3778924]

14. Brown RE, Jarvis KL, Hyland KJ. Purification and characterization of glycolipid transfer protein from bovine brain. Biochim. Biophys. Acta 1990;1044:77-83. [PubMed: 2340310]

15. Wong M, Brown RE, Barenholz Y, Thompson TE. Glycolipid transfer protein from bovine brain. Biochemistry 1984;23:6498-6505. [PubMed: 6529565]

16. Mattjus P, Pike HM, Molotkovsky JG, Brown RE. Charged membrane surfaces impede the proteinmediated transfer of glycosphingolipids between phospholipid bilayers. Biochemistry 2000;39:1067-1075. [PubMed: 10653652]

17. Mattjus P, Kline A, Pike HM, Molotkovsky JG, Brown RE. Probing for preferential interactions among sphingolipids in bilayer vesicles using the glycolipid transfer protein. Biochemistry 2002;41:266-273. [PubMed: 11772025]

18. Molotkovsky JG, Manevich YM, Babak VI, Bergelson LD. Perylenoyl- and anthrylvinyl-labeled lipids as membrane probes. Biochim. Biophys. Acta 1984;778:281-288.

19. Molotkovsky JG, Mikhalyov II, Imbs AB, Bergelson LD. Synthesis and characterization of new fluorescent glycolipid probes. Molecular organisation of glycosphingolipids in mixed-composition lipid bilayers. Chem. Phys. Lipids 1991;58:199-212.

20. Bartlett GR. Phosphorus assay in column chromatography. J. Biol. Chem 1959;234:466-468. [PubMed: 13641241]

21. Lin X, Mattjus P, Pike HM, Windebank AJ, Brown RE. Cloning and expression of glycolipid transfer protein from bovine and porcine brain. J. Biol. Chem 2000;275:5104-5110. [PubMed: 10671554]

22. Mattjus P, Turcq B, Pike HM, Molotkovsky JG, Brown RE. Glycolipid intermembrane transfer is accelerated by HET-C2, a filamentous fungus gene product involved in the cell-cell incompatibility response. Biochemistry 2003;42:535-542. [PubMed: 12525182]

23. Li XM, Malakhova ML, Lin X, Pike HM, Chung T, Molotkovsky JG, Brown RE. Human glycolipid transfer protein: Probing conformation using fluorescence spectroscopy. Biochemistry 2004;43:10285-10294. [PubMed: 15287756]

24. Brown RE, Jarvis KL, Hyland KJ. Protein measurement using bicinchoninic acid: Elimination of interfering substances. Anal. Biochem 1989;180:136-139. [PubMed: 2817336] 
25. Batzri S, Korn ED. Single bilayer liposomes prepared without sonication. Biochim. Biophys. Acta 1973;298:1015-1019. [PubMed: 4738145]

26. Kremer JMH, van der Esker MW, Pathmamanoharan C, Wiersema PH. Vesicles of variable diameter prepared by a modified injection method. Biochemistry 1977;16:3932-3935. [PubMed: 901761]

27. Ruocco MJ, Shipley GG, Oldfield E. Galactocerebroside-phospholipid interactions in bilayer membranes. Biophys. J 1983;43:91-101. [PubMed: 6688367]

28. Subbarao NK, MacDonald R,I, Takeshita K, MacDonald RC. Characteristics of spectrin-induced leakage of extruded, phosphatidylserine vesicles. Biochim. Biophys. Acta 1991;1063:147-154. [PubMed: 2015254]

29. MacDonald RC, MacDonald RI, Menco BP, Takeshita K, Subbarao NK, Hu LR. Small-volume extrusion apparatus for preparation of large, unilamellar vesicles. Biochim. Biophys. Acta 1991;1061:297-303. [PubMed: 1998698]

30. Nozaki Y, Lasic DD, Tanford C, Reynolds JA. Size analysis of phospholipid vesicle preparations. Science 1982;217:366-367. [PubMed: 7089571]

31. Reers M, Elbracht R, Rudel H, Spener F. Rapid methods for the characterization of unilamellar phospholipid vesicles. Application to studies on fatty acid donor and acceptor properties of membranes and fatty acid binding proteins. Chem. Phys. Lipids 1984;36:15-28.

32. Huang C, Thompson TE. Preparation of homogeneous, single-walled phosphatidylcholine vesicles. Methods Enzymol 1974;32:485-489. [PubMed: 4475349]

33. Mattjus P, Molotkovsky JG, Smaby JM, Brown RE. A fluorescence resonance energy transfer approach for monitoring protein-mediated glycolipid transfer between vesicle membranes. Anal. Biochem 1999;268:297-304. [PubMed: 10075820]

34. Brown RE. Spontaneous transfer of lipids between membranes. Subcell. Biochem 1990;16:333-363. [PubMed: 2238008]

35. Sasaki T, Demel RA. Net mass transfer of galactosylceramide facilitated by glycolipid transfer protein from pig brain: A monolayer study. Biochemistry 1985;24:1079-1083. [PubMed: 4096889]

36. Brown RE, Sugar IP, Thompson TE. Spontaneous transfer of gangliotetraosylceramide between phospholipid vesicles. Biochemistry 1985;24:4082-4091. [PubMed: 4052384]

37. Brown RE, Thompson TE. Spontaneous transfer of ganglioside GM1 between phospholipid vesicles. Biochemistry 1987;26:5454-5460. [PubMed: 3676263]

38. Sillence DJ, Raggers RJ, Neville DCA, Harvey DJ, van Meer G. Assay for the transbilayer distribution of glycolipids: Selective oxidation of glucosylceramide to glucuronylceramide by TEMPO nitroxyl radicals. J. Lipid Res 2000;41:1252-1260. [PubMed: 10946013]

39. Mattjus P, Malewicz B, Valiyaveettil JT, Baumann WJ, Bittman R, Brown RE. Sphingomyelin modulates the transbilayer distribution of galactosylceramide in phospholipid membranes. J. Biol. Chem 2002;277:19476-19481. [PubMed: 11909867]

40. Lalanne F, Ponsin G. Mechanism of the phospholipid transfer protein-mediated transfer of phospholipids from model lipid vesicles to high-density lipoproteins. Biochim. Biophys. Acta 2000;1487:82-91. [PubMed: 10962290]

41. Wieprecht T, Beyermann M, Seelig J. Thermodynamics of the coil-R-helix transition of amphipathic peptides in a membrane environment: The role of vesicle curvature. Biophys. Chem 2002;96:191201. [PubMed: 12034440]

42. Wieprecht T, Seelig J. Isothermal titration calorimetry for studying interactions between peptides and lipid membranes. Curr. Top. Membr 2002;52:31-56.

43. Bozzato RP, Woolley D, Tinker DO. Catalytic properties of the yeast phospholipid transfer protein. Biochem. Cell Biol 1987;65:203-210. [PubMed: 3555543]

44. Helmkamp GM Jr. Wirtz KW, van Deenen LL. Phosphatidylinositol exchange protein. Effects of membrane structure on activity and evidence for a ping-pong mechanism. Arch. Biochem. Biophys 1976;174:592-602. [PubMed: 7210]

45. Machida K, Ohnishi S. Effect of bilayer membrane curvature on activity of phosphatidylcholine exchange protein. Biochim. Biophys. Acta 1980;596:201-209. [PubMed: 6243979]

46. van den Besselaar AM, Helmkamp GM Jr. Wirtz KW. Kinetic model of the protein-mediated phosphatidylcholine exchange between single bilayer liposomes. Biochemistry 1975;14:1852-1858. [PubMed: 1125202] 
47. Yoshimura T, Welti R, Helmkamp GM Jr. General kinetic model for protein-mediated phospholipid transfer between membranes. Arch. Biochem. Biophys 1988;266:299-312. [PubMed: 3190230]

48. Helmkamp GM Jr. Wirtz KWA, van Deenen LLM. Phosphatidylinositol exchange protein. Effects of membrane structure on activity and evidence for a ping-pong mechanism. Arch. Biochem. Biophys 1976;174:590-600.

49. Rao CS, Lin X, Malakhova ML, Pike HM, Molotkovsky JG, Brown RE. Glycolipid transfer protein interacts with bilayer vesicles during in vitro protein mediated transfer of glycolipids. Biophys. J 2004;86:363a.

50. Abe A, Yamada K, Sakagami T, Sasaki T. A fluorimetric determination of the activity of glycolipid transfer protein and some properties of the protein purified from pig brain. Biochim. Biophys. Acta 1984;778:239-244. [PubMed: 6498190]

51. Pownall HJ, Hickson DL, Smith LC. Transport of biological lipophiles: Effect of lipophile structure. J. Am. Chem. Soc 1983;105:2440-2445. 


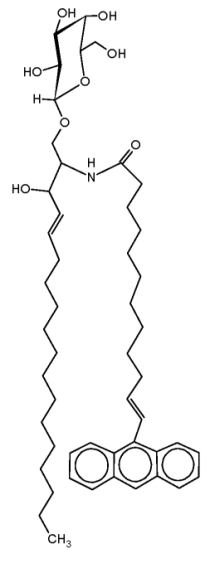

A
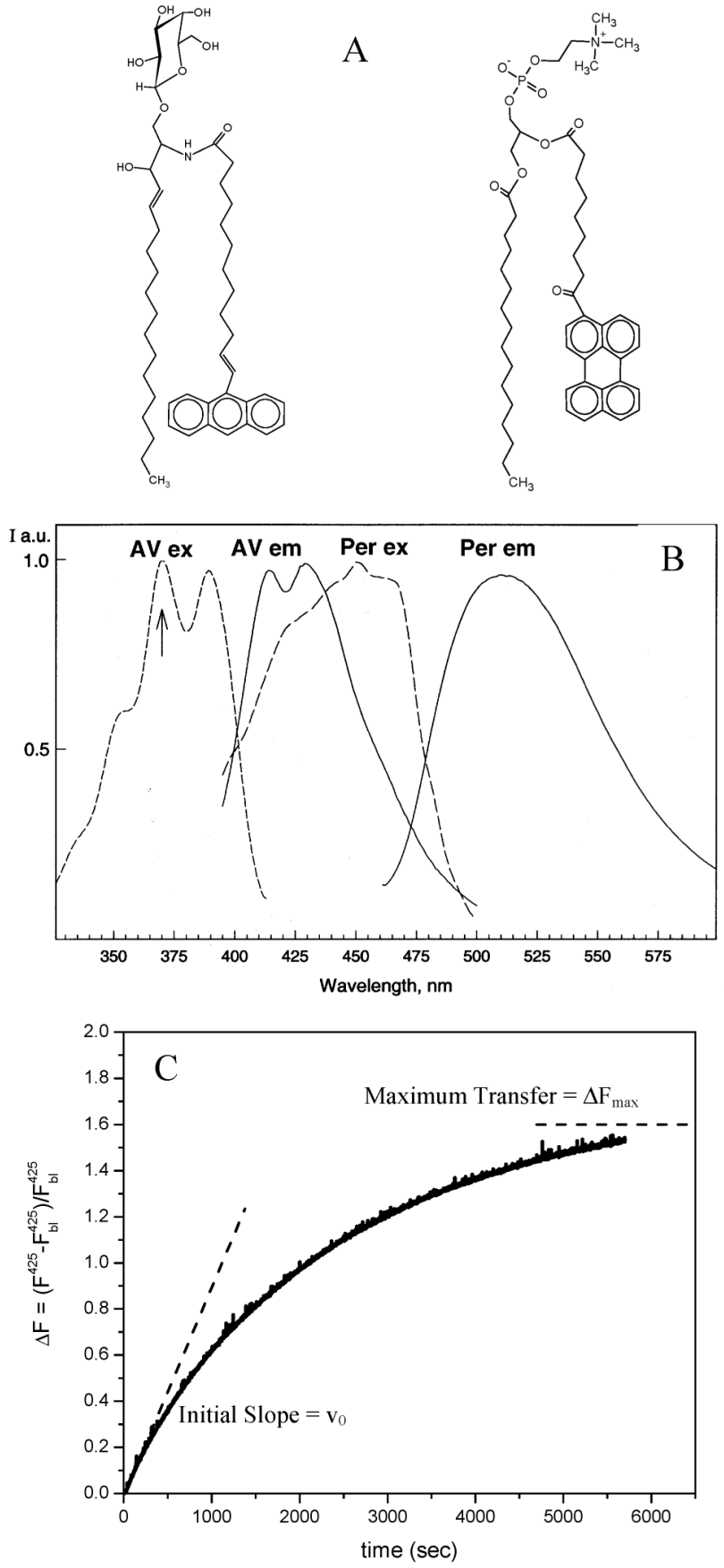

Figure 1.

General structures and excitation/emission properties of fluorescent lipids and typical response observed during glycolipid intervesicular transfer. (A) Chemical structure of galactosylceramide with an attached anthrylvinyl group (left) and PC with an attached 3perylenoyl group (right). (B) Excitation and emission spectra for anthrylvinyl and perylenoyl groups. (C) Typical kinetic response for the transfer of AV-GalCer mediated by GLTP.

Estimates for the initial slope, $v_{0}$, and the maximum transfer, $\Delta F_{\max }$, are obtained by a nonlinear regression of the experimental curve as explained in the Experimental Procedures. Standard deviations were calculated at a $95 \%$ confidence interval. $R^{2}$ values for all of the regressions were $>0.96$. 

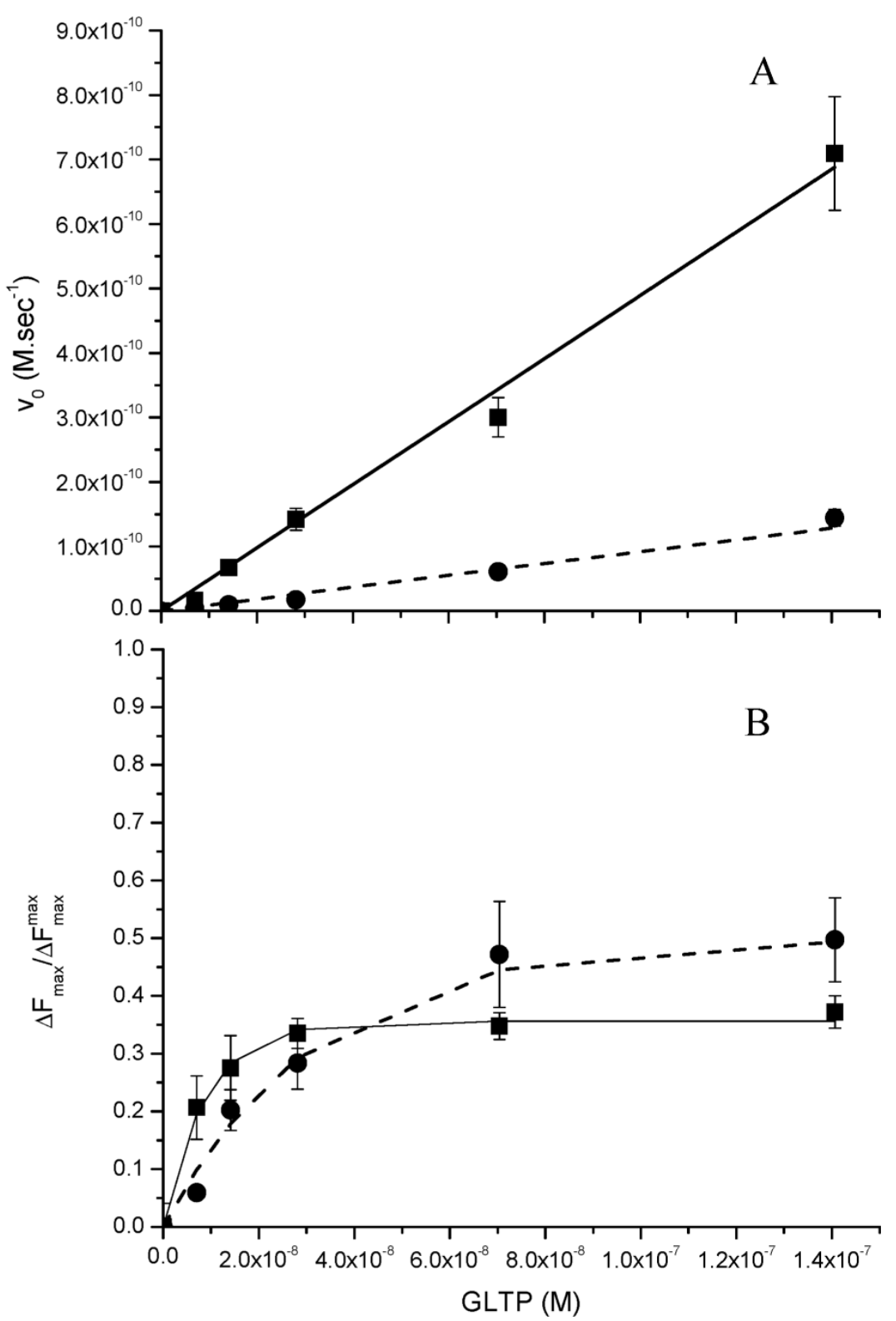

Figure 2.

(A) Molar initial velocity of transfer, $v_{0}$, as a function of the GLTP bulk concentration for SUV (घ) and LUV (•) donor vesicles. The solid (-) and dashed (- - -) lines represent the linear fit for SUVs (slope ) $4.9 \pm 0.2 \times 10^{-3} \mathrm{sec}^{-1}, R^{2}=0.99$ at $95 \% \mathrm{CI}$ ) and LUVs (slope $=9.2 \pm 0.5 \times$ $10^{-4} \mathrm{sec}^{-1}, R^{2}=0.97$ at $95 \% \mathrm{CI}$ ), respectively. The error bars represent the standard deviation of three experiments performed at $37^{\circ} \mathrm{C}$ in $3 \mathrm{~mL}$ of $\mathrm{PBS}$ at $\mathrm{pH}$ 7.4. (B) Maximum transfer of $\mathrm{AV}-\mathrm{GalCer}$, expressed as a fraction of the total accessible pool, $\Delta F_{\max } / \Delta \mathrm{F}_{\max }^{\max }$, in $\mathrm{SUV}(\boldsymbol{\square})$ and LUV $(\bullet)$ donors, as a function of the GLTP bulk concentration. The total pool was calculated by assuming that for LUVs, AV-GalCer distributes equally between the inner and the outer leaflets of the bilayer. The solid (-) and dashed (- - ) lines represent the single-exponential fit for SUVs $\left(\Delta F_{\max }^{\infty} / \Delta \mathrm{F}_{\max }^{\max }=0.36 \pm 0.02, \Delta \mathrm{F}_{\max }^{\infty}=2.1 \pm 0.1, R^{2}=0.99\right.$ at $\left.95 \% \mathrm{CI}\right)$ and LUVs $\left(\Delta F_{\max }^{\infty} / \Delta F_{\max }^{\max }=0.50 \pm 0.02, \Delta F_{\max }^{\infty}=2.9 \pm 0.1, R^{2}=0.99\right.$ at $\left.95 \% \mathrm{CI}\right)$, respectively. The error 
bars represent the standard deviation of three experiments performed at $37^{\circ} \mathrm{C}$ in $3 \mathrm{~mL}$ of PBS at $\mathrm{pH} 7.4$. 
Donor

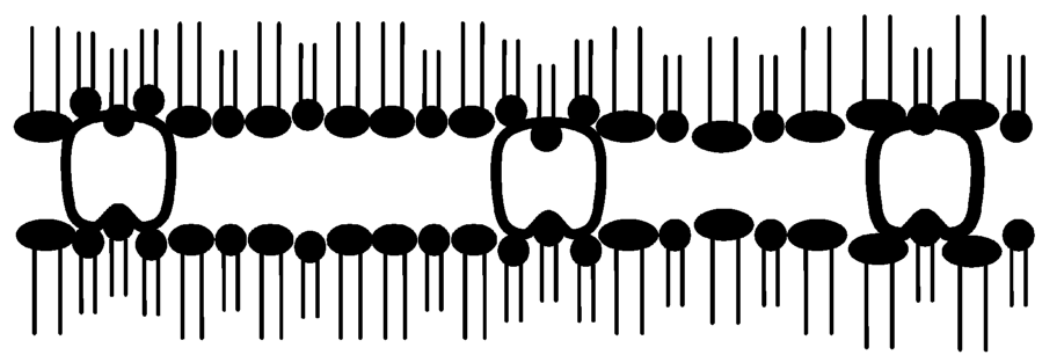

Acceptor

B

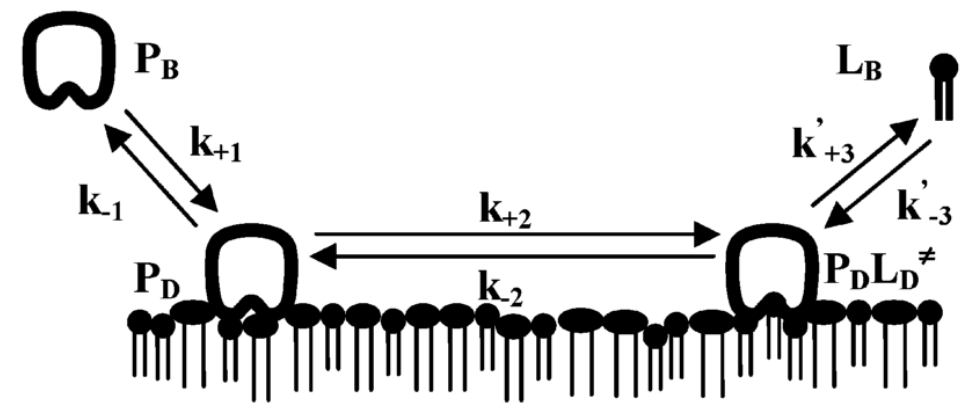

C

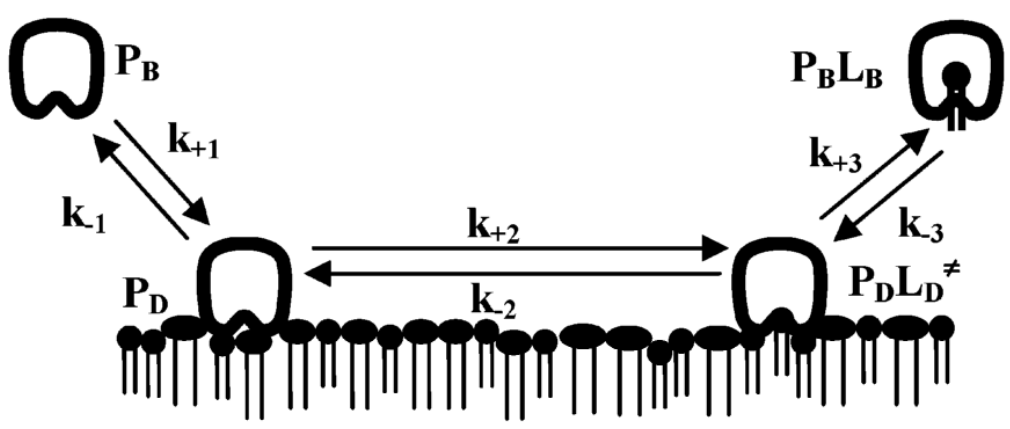

Figure 3.

(A) Schematic of the conduit mechanism of GLTP action. GLTP forms a fusion complex with the donor and acceptor allowing the exchange of GSL between the two. (B) Schematic of the bound transporter mechanism of GLTP action. GLTP from the bulk $\left(\mathrm{P}_{\mathrm{B}}\right)$ adsorbs onto the

donor surface $\left(\mathrm{P}_{\mathrm{D}}\right)$. $\mathrm{P}_{\mathrm{D}}$ then forms an activated complex $\left(\mathrm{P}_{\mathrm{D}} \mathrm{L}_{\mathrm{D}}^{\ddagger}\right)$ with the glycolipid $\left(\mathrm{L}_{\mathrm{D}}\right)$ at the interface. The complex then immediately releases $\mathrm{L}_{\mathrm{B}}$ into the bulk, whereas $\mathrm{P}_{\mathrm{D}}$ remains on the donor surface to access the remaining $\mathrm{L}_{\mathrm{D}}$ molecules. During the transfer process, $\mathrm{P}_{\mathrm{D}}$ once bound to a vesicle remains bound. (C) Schematic of the proposed free transporter mechanism of GLTP action. GLTP from the bulk $\left(\mathrm{P}_{\mathrm{B}}\right)$ adsorbs onto the donor surface $\left(\mathrm{P}_{\mathrm{D}}\right)$. $\mathrm{P}_{\mathrm{D}}$ then forms an activated complex $\left(\mathrm{P}_{\mathrm{D}} \mathrm{L}_{\mathrm{D}}^{\ddagger}\right)$ with the glycolipid $\left(\mathrm{L}_{\mathrm{D}}\right)$ at the interface. The complex is then immediately released into the bulk $\left(\mathrm{P}_{\mathrm{B}} \mathrm{L}_{\mathrm{B}}\right)$. 


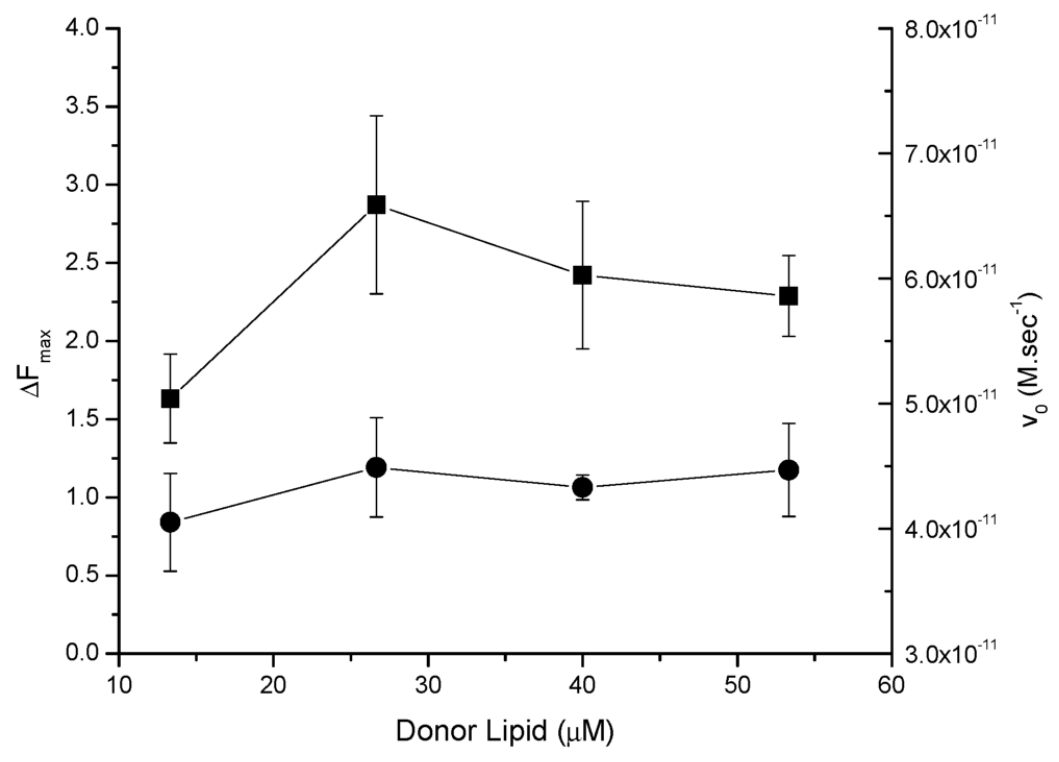

Figure 4.

Maximum transfer observed, $\Delta F_{\max }(\boldsymbol{\square})$, and the initial velocity of transfer, $v_{0}(\bullet)$, as a function of the LUV donor vesicle concentration in the assay. The error bars represent the standard deviation of three experiments performed at $37{ }^{\circ} \mathrm{C}$ in $3 \mathrm{~mL}$ of $\mathrm{PBS}$ at $\mathrm{pH}$ 7.4. 

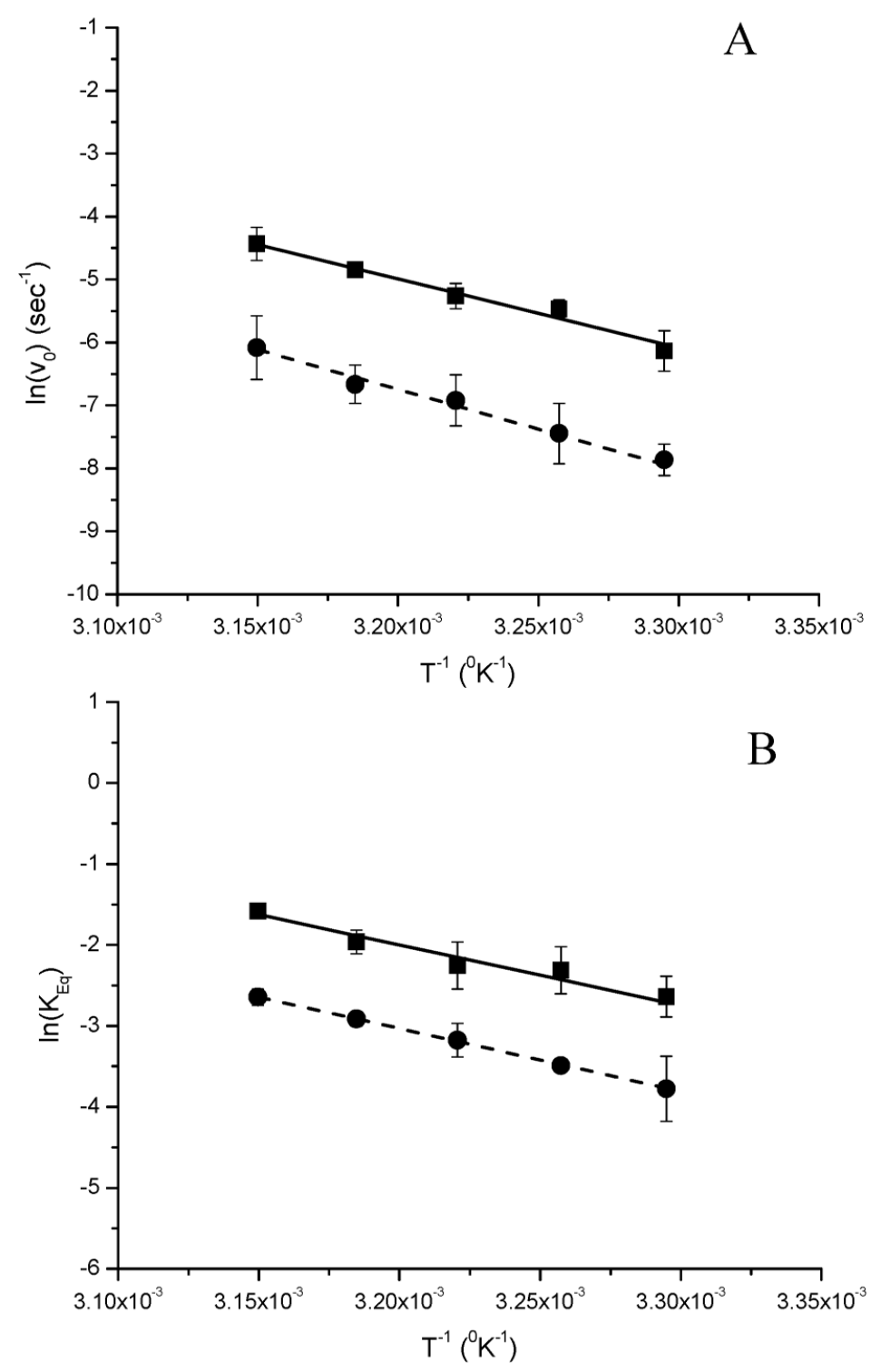

Figure 5.

(A) Arrhenius plot of the molar initial transfer rates for SUV ( $\bullet$ ) and LUV (•) donors. The error bars represent the standard deviation of three experiments. Linear regression of the

experimental data yields activation energies $\left(E_{v_{0}}^{\mathrm{a}}\right)$ of $21.7 \pm 0.4$ and $25.1 \pm 1.1 \mathrm{kcal} \mathrm{mol}^{-1}$ for SUV and LUV donors, respectively. $R^{2}$ values of the regressions were 0.99 for both SUV and LUV donors at 95\% CI. (B) van't Hoff plot of the equilibrium constants $\left(K_{\mathrm{eq}}\right)$ for SUV ( $\left.\mathbf{\square}\right)$ and LUV $(\bullet)$ donors. The error bars represent the standard deviation of three experiments. Linear regression of the experimental data yields enthalpies of transfer $\left(\Delta H_{\mathrm{eq}}\right)$ of $14.9 \pm 2.2$ and $15.4 \pm 0.3 \mathrm{kcal} \mathrm{mol}^{-1}$ for SUV and LUV donors, respectively. $R^{2}$ values of the regressions were 0.99 for both SUV and LUV donors at $95 \%$ CI. 


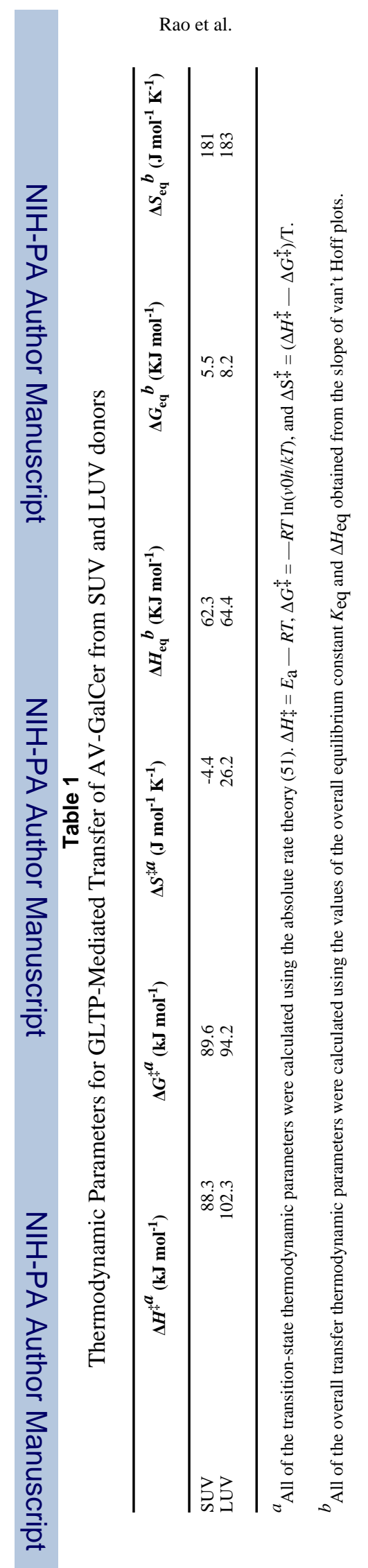

Page 23 